\title{
Assessment of Total Incapacity for Work or Incapacity in the Criminal Sense in Case of Penetrating Wounds of the Neck
}

\section{El Hadji Oumar Ndoye', Bobo Diallo², Sidy Ahmed Dia1, Mouhamed Manibiliot Soumah', Mame Coumba Fall'1, Mor Ndiaye ${ }^{1}$}

${ }^{1}$ Department of Forensic and Labor Medicine, University Cheikh Anta Diop (UCAD), Dakar, Senegal

${ }^{2}$ ENT Department of the University Hospital Center of Fann, Dakar, Senegal

Email: elhadjioumar.ndoye@ucad.ed, bobodiallo78@yahoo.fr,drsidydia@gmail.com, soumahmahmoud@yahoo.fr, mcgaye53@gmail.com

How to cite this paper: Ndoye, El H.O., Diallo, B., Dia, S.A., Soumah, M.M., Fall, M.C. and Ndiaye, M. (2018) Assessment of Total Incapacity for Work or Incapacity in the Criminal Sense in Case of Penetrating Wounds of the Neck. Forensic Medicine and Anatomy Research, 6, 1-9.

https://doi.org/10.4236/fmar.2018.61001

Received: November 27, 2017

Accepted: January 15, 2018

Published: January 18, 2018

Copyright $\odot 2018$ by authors and Scientific Research Publishing Inc. This work is licensed under the Creative Commons Attribution International License (CC BY 4.0).

http://creativecommons.org/licenses/by/4.0/

\begin{abstract}
Penetrating wounds of the neck are often life-threatening. The victims are exposed to vascular and laryngotracheal lesions. The purpose of this work is to report the various aspects of the management of penetrating wounds in our context and to make the medico-legal assessment of incapacity in the criminal sense or total incapacity for work. This is a retrospective study (2002-2014) on thirty-nine (39) cases of penetrating neck wounds, received at the ENT departments of the Aristide Le Dantec and Fann University Hospital Centers. Patients were predominantly male, representing $94 \%$ of cases with an average age of 27 years. Seventy (70\%) of the accidents occurred in the region of Dakar. In $42 \%$ of cases, the circumstance of occurrence was a fight or an assault. The weapon used in most cases by the aggressor was a cutter or a knife. The average waiting time was 37 hours with extremes of 02 and 216 hours. Surgically, all patients had been examined under general anesthesia. In terms of lesions, 37 cases had profound cervical muscle injuries, i.e. 94\%. There were 17 vascular lesions (43\%). The medico-legal distribution of patients showed that among them, $10 \%$ had a total incapacity to work exceeding 21 days. The determination of total incapacity for work is an important medical procedure that requires capability and experience. The doctor must not fall into the trap of the confusion between the TIW on the criminal level and the TIW on the civil level. He must limit medically and should not make judgments.
\end{abstract}

\section{Keywords}

Penetrating Neck Wounds, Assessment of Total Incapacity for Work, Criminal Incapacity, Forensic Medicine 


\section{Introduction}

Penetrating neck wounds are deemed difficult to assess because they concern a complex anatomical region, where several vital structures are concentrated in a small space [1]. Therefore, the risk of vascular, upper air, neurological and/or pharyngo-oesophageal injury is real.

It is difficult to estimate the frequency of these wounds because the majority of the victims die at the scene of the accident or during their evacuation. In Europe, the incidence is 1.3 per 100,000 inhabitants per year [2]. The frequency is much higher in the series that relate to the experience of the North American (48\%) and South Africans (40\%) teams [3]. Penetrating traumas are uncommon in France they represent 10 up to $15 \%$ of trauma. White knives are the main agents involved, $65 \%$ of penetrating injuries. On the other hand, they are more important in the United States with a predominance of firearms [4].

This study recalls that penetrating neck wounds are considered serious injuries. Consequently, they must normally cause a total incapacity for work more than twenty-one days when the medical certificate of voluntary injury is issued. It will provide a better orientation to the doctor when issuing total incapacity for work in the criminal sense to enlighten the judge on the seriousness of penetrating wounds of the neck.

The objectives of this work are to report on the different aspects of the management of penetrating wounds and assess on the medico-forensic level the incapacity in the legal sense or total incapacity for work (TIW).

\section{Methodology}

\subsection{Study Location}

The study was at Aristide Le Dantec and Fann Hospital's Centers services in Senegal. The FANN National University Hospital Center includes one of the five (5) ENT and Cervico-Facial Surgery departments in the capital.

Since September 2009, the ENT department of the Fann Hospital has replaced that of the Aristide Le Dantec Hospital. It is a center serving:

- Care like specialized ENT consultations, functional explorations (audiograms), head and neck surgeries and hospitalization.

- Research activities in the field of ENT and head and neck surgery are being conducted in this university-based service.

\subsection{Study Type}

This is a retrospective study from January 2002 to May 2014.

\subsection{Study Population}

The data was collected on the basis of patients' medical records of 50 cases of penetrating neck wounds received at the ENT departments of the Aristide Le Dantec and Fann University Hospital Centers. 
- Inclusion criteria

Patients, who had a cervical penetrating wound with a crossing of the platysma, were included in this study.

- Exclusion criteria

Excluding thus all patients who had suicides attempts and incomplete folders.

\subsection{File Analysis Methodology}

All the data were collected from patient records and then recorded on an Excel form for analysis using the software: SSPI, Excel and Sphinx.

\subsection{Ethical Considerations}

All the data were collected from patient records and then recorded on an Excel form for analysis using the software: SSPI, Excel and Sphinx.

\section{Results}

During the period of our study from January 2002 up to May 2014, fifty (50) patients were received for a penetrating neck wound, thirty-nine (39) records were exploitable.

\subsection{Epidemiological Data}

\subsubsection{The Sex}

The patients were predominantly male, i.e. $94 \%$ of the cases.

\subsubsection{The Age}

The average age of our population was 26.9 years with extremes of 04 and 60 years $($ standard deviation $=12.89$ ). The most significant age group was 21 to 50 years old.

\subsubsection{The Source}

Seventy percent (70\%) of the accidents occurred in the region of Dakar.

The most frequently used means of transportation was personal transportation (40\%).

\subsubsection{The Circumstances of Occurrence and Object}

In $42 \%$ of cases, the circumstance of occurrence was a fight or an assault.

The weapon used in most cases by the aggressor was a cutter or a knife.

\subsection{Therapeutic Care}

\subsubsection{Support Time}

The average waiting time for medical care was 37 hours with extremes of 02 and 216 hours.

\subsubsection{Medical Treatment}

Fourteen patients (14\%) received a blood transfusion (average of 2.4 pockets per patient). All patients received serotherapy, tetanus vaccination and antibiotic 
therapy.

The pain was relieved with analgesics (level I and II) and anti-inflammatories.

\subsubsection{Surgical Treatment}

Surgically, all patients had been examined under general anesthesia. Five patients (10\%) had a tracheotomy. Endoscopy was performed on 5 patients (10\%).

\subsection{Anatomical Lesions}

In terms of lesions, 37 cases had profound cervical muscle injury, i.e. 94\%. There were 17 vascular lesions (43\%), including 01 common carotid wound and 07 internal jugular vein wounds.

\subsection{Evolution and Complications}

In short term, there was one case of cervical subcutaneous emphysema, one case of peripheral facial palsy and one case of recurrent nerve palsy on the right.

In the long run all our patients have been lost to follow-up.

\subsection{Medico-Legal Aspects}

The medico-legal distribution of patients revealed that among them, $10 \%$ had a total inability to work for more than 21 days. The majority of patients i.e. 90\% had a total inability to work less than 21 days.

\section{Discussion}

The patients in our study were lost during their long-term follow-up. This situation did not allow us to follow the court decisions of patients who had decided to go to court. Also, the initial medical certificates were only taken into account the analysis of total work disability. The loss of sight of the patients was at the origin of the absence of the addition of the prolongations of the incapacities for some patients.

The penetrating wounds of the neck are characterized by their noisy appearance and generally favorable evolution [5]. They have become rare in civil practice in some northern countries. However, they are frequent in developing countries [5] [6] with a frequency hard to assess, because the majority of patients die during evacuation to the hospital or at the scene of the accident. This could be explained by uncontrolled urbanization in those countries, exclusion and balkanization.

This pathology is of interest to young men [5] [7]: which corroborates our series with $94 \%$. The majority of patients came from the region of Dakar. The average number of annual cases is $2-4$ in 10 years [6]. Assaults (44\%) are in the foreground; this phenomenon is explained by the recrudescence of insecurity in urban areas.

The nature of the harming agent is variable. The knife or the cutter, used during fight or assault is at the origin of apparently benign lesions. These lesions 
are found deeper, broader and often more severe during surgical exploration (one of the common carotid wound and 07 wounds from the internal jugular vein in our series). These sharp objects were found in $60 \%$ of cases as etiological agents. These figures are in line with Tall's work [8], which recorded 23 cases (54.76\%) in 2004.

Gunshot injuries are the most serious in penetrating neck trauma, however, our series did not include them. The determination of the nature of the weapon is also important, since the carriage or use of unauthorized firearms constitutes a severely repressed offense. The location, number and severity of the injuries may inform the judge on the author of the assault's motive or criminal intent, or contain aggravating circumstances. However, in case of parricide, the sanctions are more serious.

The vessels of the neck are the most frequently damaged structures during penetrating cervical trauma, which is a source of various complications: airway obstruction, hemorrhage, cerebral ischemia, air embolism, aneurism or fistula formation [9]. A quarter of penetrating cervical trauma is accompanied by vascular lesions, the most common are juvenile and subclavian vessels [10]. We found 34\% of vascular lesions including $76.5 \%$ venous lesions in our study.

Among the lesions of the cervical vessels, carotid arteries trauma are particularly serious, the majority of patients requiring urgent respiratory management [11]. The primitive carotid is more often injured, than its internal and external branches due to its high division at the cervical level [12]. Carotid lesions can compromise cerebral vascularization, which is dependent $90 \%$ on internal carotid flow and only $10 \%$ on vertebral flow.

The management of a penetrating cervical wound begins with clinical examination [13]. This highly important examination allows individualizing two groups of patients. The first group is made up of stable patients without apparent serious lesions; for them either surveillance or additional tests are performed. The second group concerns unstable patients or patients with lesions whose surgery cannot be delayed [1] [14]. In all cases, the severity of the lesions must be evaluated. This evaluation is based on clinical criteria. These criteria help to evaluate all the vital structures that make up the neck. They represent a true therapeutic decision-making tool. The attitude towards a decision for cervicotomy, must be neither wait-and-see nor interventionist. Medical treatment is required during this monitoring period [5]. An exploratory cervicotomy was performed within 24 hours on all the patients in our series (100\%). Five tracheotomies, or $12 \%$ were performed. This highlights the importance of these two therapeutic methods in our practice.

This short intervention period demonstrates an improvement in both technical and human management. Twenty-one (21) patients benefited from a delayed surgery. Our practice is characterized by the difficulty in performing paraclinical examinations in emergency. However, when it comes to stable patients without "serious" lesions, it is necessary to take time to carry out necessary complemen- 
tary examinations (Pharyngo-oesophageal transit, cervical angio-tomodensitometry, nuclear magnetic resonance imaging, arteriography or Doppler ultrasound of the vessels of the neck). This is what MacFarlane [15] Demetriades [3] and Moeng [14] suggest.

However, after the medical care, the doctor must determine a total incapacity for working as requested by victims. Total incapacity for work or incapacity in the criminal sense is an incapacity experienced by the victim to perform all the actions of everyday life (washing, going to the bathroom, getting dressed, feeding, moving, etc.) as a result of assault and battery they were subjected to. This delay differs depending on whether it is an adult, a child, an infant or an elderly person [16]. It is different from temporary occupational or economic incapacity or incapacity in the civil sense that applies to persons under employment.

Total incapacity for work is difficult to determine because it must take into account the objective lesions (location, nature and severity of lesions), their functional impact and the duration of the care provided. This is the period during which the individual is not in a total capacity to engage in the usual acts of everyday life, for physical or psychological reasons. It is always fixed subject to complications and may later be subject to a surcharge. Psychological trauma is rarely taken into account in our context. This, because of the subjective side of its assessment and or the ignorance of doctors. However, it will be taken into account only if major, obviously handicapping for the victim and objectivized by medical consultations with prescription of psychotropic drugs [17].

In our series, total incapacity for work in the criminal sense was $10 \%$. Our study show that the total work disability delivered to patients is underestimated in view of the injuries caused. Penetrating wounds in the neck are serious injuries and should be totally off for more than twenty-one days. All patients were operated on and hospitalized. The doctor must know that the penetrating wounds of the neck carry a risk of injury to a vital organ. They are formidable because part of the lesions can be unnoticed. Their physical and psychological injuries in this context of trauma constitute major elements to allow the doctor to issue them a total incapacity for work of more than twenty one days.

The TIW once retained, incurs the criminal or civil liability of the perpetrator of unintentional assault. According to the provisions of Articles 294 and 296 of the Senegalese criminal code, intentional injury leading to a more than 20 days TIW result in a sentence of 1 year to 5 years for its author and a fine from CFA 20,000 to CFA 250,000, on the other hand, when the TIW is less than 20 days, the guilty party will be punished with imprisonment of 1 month to 2 years and a fine of 20,000 to 100,000 CFA [18].

Currently, there is no objective scale of TIW assessment available to physicians who are required to write medical certificates of assault. The doctor, whether forensic or not, will propose a period of total incapacity for work after a clinical examination, more or less completed by additional examinations.

This total incapacity corresponds to physical and mental harm that the victim 
can undergo. The writing is done on letterhead upon request from the patient or on request from the judicial authority. The delivery of the medical certificate must be made by hand to the victim or in case of requisition to the judicial authority.

Voluntary assault is more severely punished in certain aggravating circumstances: on a person under the age of 15 , on persons who are particularly vulnerable because of their age, illness, disability, physical or mental disability, apparent pregnancy or known to the author, an ascendant or adoptive parent, a spouse or a cohabiting partner.

However, often there are large disparities between doctors, in fixing the TIW for the same type of traumatic lesion, and sometimes even the same doctor can fix different TIW for 2 victims with similar injuries [19].

In practice, doctors are under pressure to write in the initial medical certificate a period of total incapacity for work of more than twenty days so as to immediately give the offense a correctional nature [20]. As Soumah attests in his study, the victims are in the " 21 day certificate race". This frantic search is due to the fact that the victims of assault in addition to the compensation to which they aspire, want to see the authors of the facts incarcerated. There is therefore sometimes a "real bargain" between doctors and victims, for an over-estimation of the duration of TIW [21].

To avoid disparity in the fixation of TTIs for the same type of traumatic injury, the criminal certificate must be written or validated by a forensic pathologist. Consequently, the poorly drafted certificate can serve the victim, aggravate the sanction for the person responsible, push the magistrate to renew the examination or question the doctor's criminal, civil and ordinal liability.

\section{Conclusions}

Penetrating neck wounds are an emergency and are considered difficult to be evaluated. Their seriousness depends on vascular impact, upper aero6digestive and neurological ways, the affected anatomical area and the nature of the wounding agent. The principles of management are based on a rigorous initial medicalization. But despite the evolution of their management, exploratory tracheostomy and cervicotomy still play an important role in our practice.

The surgery must be performed within the first 24 hours. Only this early, complete and adapted surgical treatment can improve the functional prognosis of patients and avoid the constitution of stenosis which may require iterative endoscopies aggravating the sufferings endured. The lesions should be well described in the initial medical certificate which has consequences on both the victim and the aggressor.

The determination of total incapacity for work is an important medical procedure that requires capability and experience. The doctor must not fall into the trap of the confusion between the TIW on the criminal level and the TIW on the civil level. He must limit medically and should not make judgments. 


\section{Conflict of Interest}

There is no conflict of interest regarding this article, and the article has not been supported by any foundation.

\section{References}

[1] Thoma, M., Navsaria, P.H., Edu, S. and Nicou, A.S. (2008) Analysis of 203 Patients with Penetrating Neck Injury. World Journal Surgery, 32, 2716-2723. https://doi.org/10.1007/s00268-008-9766-7

[2] Pakarinen, T.K., Leppananimi, A., Shivo, E., Hiltunen, K.M. and Salo, J. (2006) Management of Cervical Stab Wounds in Low Volume Trauma Centres: Systematic Physical Examination and Low Threshold for Adjunctive Studies, or Surgical Exploration. Injury, 37, 440-447. https://doi.org/10.1016/j.injury.2006.01.044

[3] Demetriades, D., Theodoru, D., Cornell, E., Berne, T.V., et al. (1997). Evaluation of Penetrating Injuries of the Neck: Prospective Study of 223 Patients. World Journal Surgery, 21, 41-48. https://doi.org/10.1007/s002689900191

[4] Monneuse, O.J., Barth, X., Gruner, L., Pilleul, F., Valette, P.J., Oulie, O., et al. (2004) Abdominal Wound Injuries: Diagnosis and Treatment. Report of 79 Cases. Annales De Chirurgie, 129, 156-163. https://doi.org/10.1016/j.anchir.2004.01.013

[5] Clavier, N. (1996) Particularités des traumatismes pénétrants cervico-faciaux chez l'adulte. Médecine d'urgence, Société Française d'anesthésie-Réanimation, ed. Masson, Paris, 75-86.

[6] Barriot, P. and Riou, B. (1988) Retrograde Technique for Tracheal Intubation in Trauma Patients. Critical Care Medicine, 16, 712-713. https://doi.org/10.1097/00003246-198807000-00014

[7] Saletta, J.D., Lowe, R.J., Lim, L.T., Thornton, J., Delk, S. and Mmoss, G.S. (1976) Penetrating Trauma of the Neck. Journal Trauma, 16, 579-587. https://doi.org/10.1097/00005373-197607000-00011

[8] Tall, A., Sy, A., Diouf, R., Ndiaye, I.C., et al. (2004) Notre expérience des traumatismes de cou en pratique civile: à propos de 45 cas. Médecine d'Afrique Noire, 5104, 199-202.

[9] Steenburg, S.D., Sliker, C.W., Shanmuganathan, K. and Siegel, E.L. (2010) Imaging Evaluation of Penetrating Neck Injuries. Radiographics, 30, 869-886. https://doi.org/10.1148/rg.304105022

[10] Bishara, R.A., Pasch, A.R., Douglas, D.D., Schuler, J.J., Lim, L.T. and Flanigan, D.P. (1986) The Necessity of Mandatory 14 Exploration of Penetrating Zone II Neck Injuries. Surgery, 100, 655-660.

[11] Meyer, J.P., Barret, J.A., Schuler, J.J. and Flanigan, D.P. (1987) Mandatory vs Selective Exploration for Penetrating Neck Trauma. A Prospective Assessment. Archives of Surgery, 122, 592-597. https://doi.org/10.1001/archsurg.1987.01400170098014

[12] Rubio, P.A., Reul, G.L., Beall, A.C., Jordan, G.L. and Debakey, M.E. (1974) Acute Carotid Artery Injury: 25 Years' Experience. The Journal of Trauma, 14, 967-973. https://doi.org/10.1097/00005373-197411000-00010

[13] Diop, E.M., Kayibanda, E., Fall, B., Diop, A. and Diop, L.S. (1998) Plaies pénétrantes du cou (à propos de 4 cas). The Annals of Otology, Rhinology, and Laryngology, 100, 513-518.

[14] Moeng, S. and Boffard, K. (2002) Penetrating Neck Injuries. Scandinavian Journal of Surgery, 91, 34-40. https://doi.org/10.1177/145749690209100106 
[15] Macfarlane, C. and Benn, C.A. (2002) Penetrating Neck Injury: A Review. Trauma, 4, 79-90. https://doi.org/10.1191/1460408602ta226oa

[16] Lorin de la Grandmaison, G. and Michel, D. (2006) Incapacité totale de travail: Proposition d'un barème indicatif. La Revue du Praticien-Médecine Générale, 20, 718-719.

[17] Manaouil, C., Pereira, T., Gignon, M. and Jardé, O. (2011) La notion d'incapacité totale de travail (TIW) dans le Code pénal. La Revue de Médecine Légale, 2, 59-71. https://doi.org/10.1016/j.medleg.2011.03.002

[18] Loi n¹965-60 du 21 juillet 1965 portant Code pénal-Sénégal articles 294 et 296.

[19] Baccino, E. (2006) Médecine de la violence: Prise en charge des victimes et des agresseurs. Chapitre 4: Victimes des violences physiques (aspects pénaux). Elsevier, Masson, 76-139.

[20] Yapo, E.H., Khemakhem, Z., Tilhet-Coartet, S., Fanton, L., Miras, A. and Malicier, D. (1999) Coups et blessures volontaires: Le médecin légiste est avant tout un clinicien. Journal de Médecine Légale-Droit Médical, 42 , 109-113.

[21] Soumah, M.M., Elame Ngwa, H.E., Ndiaye, M. and Sow, M.L. (2011) Qualité des certificats de coups et blessures volontaires sur adultes à Dakar et Diourbel, Sénégal. The Pan African Medical Journal, 10, 59. 